\title{
Studies of Electrocardiographic Patterns in Cases with Neurosurgical Lesions
}

\author{
Shiro HAYASHI, M.D., Jyokichi WATANABE, M.D., \\ Seiichiro MIYAGAWA, M.D., Shioetsu TAMAKUMA, M.D., \\ and Hisamitsu NAGAKI, M.D.
}

Recent studies on the electrocardiographic patterns in cases with cerebrovascular accidents have shown that a neural factor might be responsible for the abnormalities in the electrocardiograms, but we have as yet very little clinical information in cases with neurosurgical lesions. The purposes of this presentation are to describe the pre- and postoperative electrocardiographic patterns and to discuss the possible causes inducing abnormalities in the postoperative electrocardiograms.

Evidence is presented in 323 neurosurgical cases that the high incidence of abnormal electrocardiographic patterns, especially flat or inverted $\mathrm{T}$ waves and $\mathrm{S}-\mathrm{T}$ segments depression, are exhibited postoperatively in cases with supratentorial lesions, especially with craniopharyngioma, hypophyseal adenoma and other sellar tumors and with the fronto-temporal lobe tumors.

From the results of this study, it may be suggested that in cases with neurosurgical lesions, electrocardiograms may also be affected by a neural factor from surgical damage to the parapituitary areas of the central nervous system.

TN our previous paper, ${ }^{1)}$ various factors such as age, cardiovascular Impairment (hypertension, arteriosclerosis, enlargement of the heart etc.), impaired liver function, electrolytes imbalance etc., have been considered as causing postoperative abnormalities in electrocardiograms. Apart from these, the site of the operation should also be considered as another additional causal factor.

Recent studies on electrocardiographic patterns in cases with cerebral trauma, ${ }^{2-3)}$ cerebrovascular accidents ${ }^{(1)-11)}$ or with pneumoencephalography ${ }^{1218}$, have shown both cerebral and cardiac findings on many occasions, and suggested that a neural factor might be responsible for the abnormality in the electrocardiograms. However, during the past couple of decades electrocardiographic patterns have rarely been observed in cases with brain tumors. Aschenbrenner and Bodechtel ${ }^{19)}$ reported that, in electrocardiograms in younger patients with brain tumors, premature beats,

From the Department of Surgery (Chief: Prof. Kentaro Shimizu, M.D.), Tokyo University School of Medicine, Tokyo, Japan. 
abnormal $\mathrm{T}$ waves and S-T segments, etc. were disclosed frequently after brain surgery. In Bartelheimer's paper, ${ }^{20)}$ electrocardiograms revealed arrhythmias and S-T segments depression in most of the cases with acromegaly.

But, we have as yet very little clinical information as to whether or not any special area in the brain is connected with the induction of the abnormalities in the electrocardiograms. Therefore, the purposes of this presentation are to describe the pre- and postoperative electrocardiographic patterns and to discuss the possible mechanisms of the development of abnormalities in the electrocardiograms in cases with neurosurgical lesions.

\section{Material And Method}

Three hundred and twenty-three cases with various neurosurgical lesions admitted to the Surgical Department of Tokyo University Hospital, between September, 1957 and March, 1960, comprise the materials of this study. The diagnosis was accepted only if proved by one or more of the following clinical and laboratory findings: the history and clinical course of the present illness, neurological examination, X-ray diagnosis, electroencephalograms, etc.: or at surgery, or even at autopsy. Electrocardiograms were taken frequently at the preand postoperative periods in each case.

\section{REsULts}

Preoperative electrocardiograms in cases with neurosurgical lesions.

The incidence of abnormal $\mathrm{T}$ waves (flat or inverted $\mathrm{T}$ waves), $\mathrm{S}-\mathrm{T}$

Table I. Incidence of Preoperative Abnormal Patterns in the Electrocardiograms 5) Intracranial vascular (15 cases)
anomaly

$6.7 \% \quad 13.3 \%$
$3.9 \% \quad 3.9 \%$
$6.7 \%$
6) Depressed fracture of (15 cases) the skull
7) Intracranial
(16 cases) $\quad 6.3 \%$ hematoma
(13 cases)
$7.7 \%$
$7.7 \%$
$7.7 \%$
$7.7 \%$
$6.7 \%$
$6.3 \%$
8) Head injury

(13 cases) 
segments depression, Q-T interval prolongation and premature beats in the electrocardiograms checked before the surgery differed among different kinds of lesions (Table I).

Abnormal patterns of electrocardiograms, such as flat or inverted $T$ waves, S-T segments depression, Q-T interval prolongation and premature beats were of the highest incidence in cases with head injury followed by cases with lesions at the sellar region, intracranial vascular anomaly, supratentorial tumors, infratentorial tumors, spinal cord tumors and chronic intracranial hematoma in that order of decreasing incidences. In our previous paper, ${ }^{1}$ it was shown, that there was a significant difference in the incidence of abnormal electrocardiograms among various age groups in cases of general surgery - the older the patient, the higher the incidence of abnormal patterns. Although our cases with neurosurgical lesions consisted of rather younger-aged patients, it appeared obvious that there was a little difference of preoperative abnormal electrocardiograms between neurosurgical and general surgical cases even in the same age groups (Table II).

Table II. Incidence of Preoperative Abnormal $\mathrm{T}$ Waves and S-T Segments Depression in Various Age-brackets of Cases with Gastric Pathology (Gastric Cancer and Ulcer) and with Neurosurgical Lesions

a. Cases with gastric pathology

$\begin{array}{lcccccc}\text { Age } & \begin{array}{c}0-29 \\ (34 \text { cases })\end{array} & \begin{array}{c}30-39 \\ (43 \text { cases })\end{array} & \begin{array}{c}40-49 \\ 48 \text { cases })\end{array} & \begin{array}{c}50-59 \\ (94 \text { cases })\end{array} & \begin{array}{c}60-69 \\ (74 \text { cascs })\end{array} & \begin{array}{c}70- \\ (17 \text { cases })\end{array} \\ \begin{array}{c}\text { 1-Flat T waves or slight de- } \\ \text { pression of S-T segments } \\ \text { (below 0.1 mV.) }\end{array} & 2.3 \% & 2.1 \% & 3.3 \% & 8.4 \% & 11.7 \% \\ \begin{array}{l}\text { 2-Inverted T waves or marked } \\ \text { depression of S-T segments } \\ \text { (over 0.1 mV.) }\end{array} & 2.3 \% & 2.1 \% & 2.1 \% & 1.1 \% & \\ \quad & & & & & & \\ \text { Total } & 4.6 \% & 4.2 \% & 5.4 \% & 9.5 \% & 11.7 \%\end{array}$

b. Cases with neurosurgical lesions (including various kinds of lesions)

\begin{tabular}{|c|c|c|c|c|c|}
\hline Age & $\begin{array}{c}0-29 \\
(100 \text { cases })\end{array}$ & $\begin{array}{c}30-39 \\
(52 \text { cases })\end{array}$ & $\begin{array}{c}40-49 \\
(90 \text { cases })\end{array}$ & $\begin{array}{c}50-59 \\
(56 \text { cases })\end{array}$ & $\begin{array}{c}60- \\
(25 \text { cases })\end{array}$ \\
\hline $\begin{array}{l}\text { 1-Flat } \mathrm{T} \text { waves or slight de- } \\
\text { pression of } \mathrm{S}-\mathrm{T} \text { segments }\end{array}$ & $6.5 \%$ & $9.3 \%$ & $5.5 \%$ & $3.5 \%$ & $10.7 \%$ \\
\hline $\begin{array}{l}2 \text { Inverted } T \text { waves or marked } \\
\text { depression of } S-T \text { segments }\end{array}$ & $0.9 \%$ & $1.8 \%$ & & $7.0 \%$ & $3.6 \%$ \\
\hline Total & $7.4 \%$ & $11.1 \%$ & $5.5 \%$ & $10.5 \%$ & $14.3 \%$ \\
\hline
\end{tabular}

Postoperative electrocardiograms in cases with neurosurgical lesions.

In these cases, various kinds of neurosurgical operations were performed under endotracheal anaesthesia with Nitrous-oxide-Oxygen- Barbiturate- 
S.C.C. and serial electrocardiograms were recorded during and after the operation. The data, obtained at postoperative periods, is as seen in Table III. It is evident that high incidence of flat or inverted $\mathrm{T}$ waves,

Table III. Incidence of Abnormal Electrocardiographic Patterns Induced Postoperatively (in Cases with Preoperative

Normal Electrocardiograms)

\begin{tabular}{|c|c|c|c|c|c|c|c|}
\hline \multicolumn{8}{|c|}{ 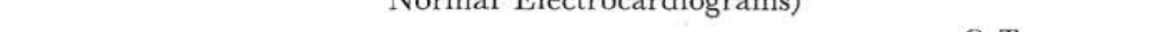 } \\
\hline & & $\begin{array}{l}\text { Abnormal } \\
\mathrm{P} \text { waves }\end{array}$ & $\begin{array}{l}\text { Flat } T \\
\text { waves }\end{array}$ & $\begin{array}{l}\text { Inverted } \\
\mathrm{T} \text { waves }\end{array}$ & $\begin{array}{c}\text { S-T } \\
\text { segments } \\
\text { depression }\end{array}$ & $\begin{array}{c}\text { Q-T } \\
\text { interval } \\
\text { prolonga- } \\
\text { tion }\end{array}$ & $\begin{array}{l}\text { Extra- } \\
\text { systoles }\end{array}$ \\
\hline $\begin{array}{l}\text { Supratentorial } \\
\text { tumors } \\
\text { (except 2) }\end{array}$ & (67 cases) & $2 \%$ & $21 \%$ & $12 \%$ & $6 \%$ & $19 \%$ & $2 \%$ \\
\hline $\begin{array}{l}\text { Craniopharyn- } \\
\text { gioma, hypo- } \\
\text { physeal adeno- } \\
\text { ma and other } \\
\text { sellar tumors }\end{array}$ & (46 cases) & $5 \%$ & $41 \%$ & $15 \%$ & $16 \%$ & $35 \%$ & $5 \%$ \\
\hline $\begin{array}{l}\text { Infratentorial } \\
\text { tumors }\end{array}$ & (47 cases) & $8 \%$ & $17 \%$ & $4 \%$ & $2 \%$ & $11 \%$ & \\
\hline $\begin{array}{l}\text { Spinal cord } \\
\text { tumors }\end{array}$ & (9 cases) & & $11 \%$ & & & $22 \%$ & $11 \%$ \\
\hline $\begin{array}{l}\text { Intracranial } \\
\text { vascular } \\
\text { anomaly }\end{array}$ & (8 cases) & & $12 \%$ & & $12 \%$ & $12 \%$ & \\
\hline $\begin{array}{l}\text { Depressed frac- } \\
\text { ture of the skull }\end{array}$ & (11 cases) & $9 \%$ & $18 \%$ & & & $9 \%$ & \\
\hline $\begin{array}{l}\text { Intracranial } \\
\text { hematoma }\end{array}$ & (15 cases) & $7 \%$ & & $13 \%$ & $13 \%$ & $7 \%$ & \\
\hline
\end{tabular}

depressed S-T segments and prolonged Q-T interval in cases with tumors at the sellar region and with supratentorial tumors, was found even in cases with essentially normal preoperative electrocardiograms. It would be interesting to elucidate at what special sites of the central nervous system that an extremely high incidence of abnormal electrocardiograms was induced postoperatively, by the analysis of more precise anatomical sites of lesions (Table IV). The incidence of abnormal S-T segments and $\mathrm{T}$ waves was $85 \%$ in 13 cases with craniopharyngioma, $67 \%$ in 24 cases with hypophyseal adenoma, $67 \%$ in 9 cases with other kinds of tumors at the sellar region, $62 \%$ in 13 cases with temporal lobe tumors and $48 \%$ in 23 cases with frontal lobe tumors, but was rather low in cases with parietooccipital lobe tumors and those with infratentorial lesions. In cases with craniopharyngiomas, hypophyseal adenoma and other sellar tumors, most of the abnormalities consisted of flat and inverted $\mathrm{T}$ waves, but the incidence of S-T segments depression was also markedly higher than in cases with infratentorial tumors. Therefore, it seemed likely that the sellar and temporo-frontal regions were the sites most predisposed in inducing the 
Table IV. Incidences of Abnormal T Waves and S-T Segments

Depression and of Prolonged Q-T Intervals (in Cases with Preoperative Normal Electrocardiograms)

\begin{tabular}{|c|c|c|c|c|c|c|c|}
\hline & & & $\begin{array}{l}\text { Flat } T \\
\text { waves }\end{array}$ & $\begin{array}{l}\text { Inverted } T \\
\text { waves }\end{array}$ & $\begin{array}{c}\text { S-T seg- } \\
\text { ments } \\
\text { depression }\end{array}$ & Total & $\begin{array}{l}\text { Prolonged } \\
\text { iQ-T } \\
\text { intervals }\end{array}$ \\
\hline 1) & Craniopharyngioma & (13 cases) & $54 \%$ & $23 \%$ & $8 \%$ & $85 \%$ & $31 \%$ \\
\hline 2) & Hypophyseal adenoma & (24 cases) & $37 \%$ & $8 \%$ & $21 \%$ & $67 \%$ & $33 \%$ \\
\hline 3) & Other sellar tumors & (9 cases) & $34 \%$ & $22 \%$ & $11 \%$ & $67 \%$ & $45 \%$ \\
\hline 4) & Temporal lobe tumors & (13 cases) & $38 \%$ & $15 \%$ & $8 \%$ & $62 \%$ & $15 \%$ \\
\hline 5) & Frontal lobe tumors & (23 cases) & $17 \%$ & $13 \%$ & $17 \%$ & $48 \%$ & $33 \%$ \\
\hline 6) & $\begin{array}{l}\text { Parieto-occipital lobe } \\
\text { tumors }\end{array}$ & (32 cases) & $19 \%$ & $9 \%$ & & $28 \%$ & $9 \%$ \\
\hline 7) & Infratentorial lesions & (47 cases) & $17 \%$ & $4 \%$ & $2 \%$ & $24 \%$ & $11 \%$ \\
\hline & Gastric cancer and ulcer & (302 cases) & $4 \%$ & $2 \%$ & $8 \%$ & $15 \%$ & $23 \%$ \\
\hline
\end{tabular}

Table V. Incidences of Postoperatively Induced Abnormal $\mathrm{T}$ Waves and S-T Segments Depression in Various Age-brackets of Cases with Gastric Pathology (Gastric Cancer and Ulcer) and with Neurosurgical Lesions (in Cases with Preoperative Normal Electrocardiograms)

a. Cases with gastric pathology

\begin{tabular}{|c|c|c|c|c|c|c|}
\hline Age & $\begin{array}{c}0-29 \\
\text { (34 cases) }\end{array}$ & $\begin{array}{c}30-39 \\
\text { (41 cases) }\end{array}$ & $\begin{array}{c}40-49 \\
(45 \text { cases) }\end{array}$ & $\begin{array}{c}50-59 \\
\text { (88 cases) }\end{array}$ & $\begin{array}{c}60-69 \\
\text { (64 cases) }\end{array}$ & $\begin{array}{l}70- \\
(15 \text { cases })\end{array}$ \\
\hline $\begin{array}{l}\text { 1-Flat } \mathrm{T} \text { waves or slight } \\
\text { depression of } \mathrm{S}-\mathrm{T} \text { segments } \\
\text { (below } 0.1 \mathrm{mV} \text {.) }\end{array}$ & $3.0 \%$ & $2.4 \%$ & $8.9 \%$ & $7.9 \%$ & $9.4 \%$ & $33.3 \%$ \\
\hline $\begin{array}{l}\text { 2-Inverted T waves or marked } \\
\text { depression of S-T segments } \\
\text { (over } 0.1 \mathrm{mV} \text {.) }\end{array}$ & $3.0 \%$ & $2.4 \%$ & $2.2 \%$ & $3.4 \%$ & $3.1 \%$ & $6.6 \%$ \\
\hline Total & $6.0 \%$ & $4.8 \%$ & $11.1 \%$ & $11.3 \%$ & $12.5 \%$ & $39.6 \%$ \\
\hline
\end{tabular}

b. Cases with neurosurgical lesions (including various kinds of lesions)

\begin{tabular}{|c|c|c|c|c|c|}
\hline Age & $\begin{array}{c}\text { C- } 29 \\
(20 \text { cases })\end{array}$ & $\begin{array}{l}30-39 \\
\text { (18 cases) }\end{array}$ & $\begin{array}{c}40-49 \\
(29 \text { cases })\end{array}$ & $\begin{array}{l}50-59 \\
\text { (16 cases) }\end{array}$ & $\begin{array}{l}60-69 \\
\text { (9 cases) }\end{array}$ \\
\hline $\begin{array}{l}\text { 1-Flat } \mathrm{T} \text { waves or slight } \\
\text { depression of S-T segments } \\
\text { (below } 0.1 \mathrm{mV} \text {.) }\end{array}$ & $15.0 \%$ & $16.7 \%$ & $34.5 \%$ & $31.3 \%$ & $22.2 \%$ \\
\hline $\begin{array}{l}\text { 2-Inverted T waves or marked } \\
\text { depression of S-T segments } \\
\text { (over } 0.1 \mathrm{mV} \text {.) }\end{array}$ & $10.0 \%$ & $5.6 \%$ & $3.5 \%$ & $12.5 \%$ & \\
\hline Total & $25.0 \%$ & $23.3 \%$ & $28.0 \%$ & $43.8 \%$ & $22.2 \%$ \\
\hline
\end{tabular}


abnormal $\mathrm{T}$ waves and $\mathrm{S}-\mathrm{T}$ segments postoperatively. On the other hand, no considerable difference could be found in the incidence of postoperatively induced abnormal S-T segments and $T$ waves between cases with 2 kinds of tumors-meningioma and glioma.

As shown in Table $\mathrm{V}$, these results apparently indicated that a marked difference in postoperative incidence of abnormal S-T segments and $T$ waves was found between cases with gastric pathology and with these neurosurgical lesions, and that the incidence of postoperative electrocardiographic abnormalities in cases of each age group with neurosurgical lesions was approximately equal to the incidence in cases with gastric pathology even when the latter group belonged to an age-bracket that was over 30 years older.

\section{Illustration of cases with abnormal electrocardiographic patterns induced after operation}

Case 1. K. T. 35-year-old male. Craniopharyngioma.

The patient was admitted to the hospital because of craniopharyngioma with hypopituitarism. Left visual acuity has been impaired since 6 year of age, and episodes of nausea, vomiting and unconsciousness occurred occasionally since he was 10 years old. A large calcified tumor was found at the base of the frontal lobes and the suprasellar region both in plain craniograms and cerebral arterio-

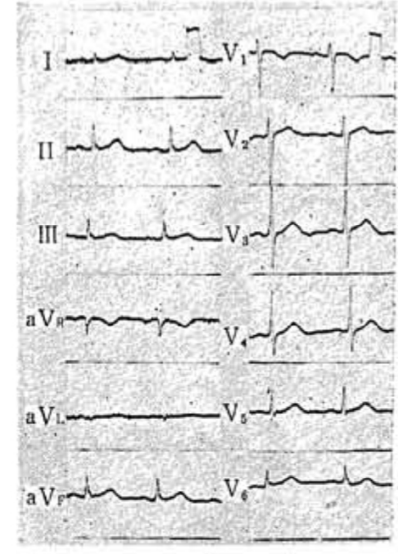

A.

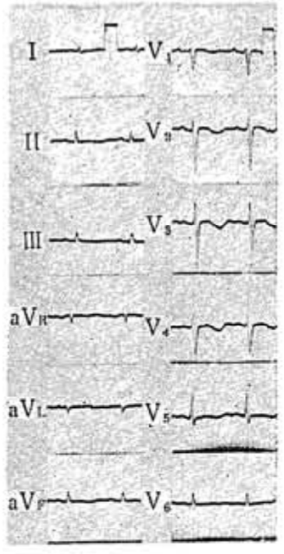

B.

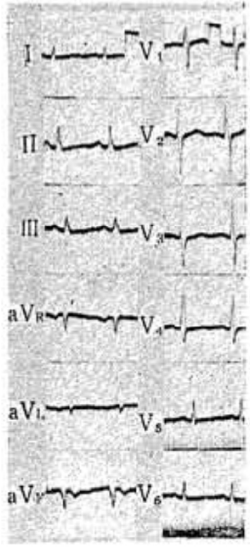

C.

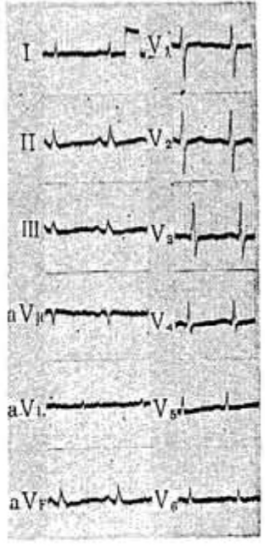

D.

Fig. 1. K. T. 35-year-old male with craniopharyngioma.

A. Preoperative electrocardiograms showed no abnormal patterns.

B. Partial removal of the tumor was done by left frontal approach under general anesthesia. Electrocardiograms revealed flat $\mathrm{T}$ waves in leads I, $\mathrm{aV}_{\mathrm{L}}, \mathrm{V}_{\mathrm{6}}$, and inverted $\mathrm{T}$ waves in leads II, III, $\mathrm{aV}_{\mathrm{F}}, \mathrm{V}_{2-5}$ immediately after operation. Blood pressure was 100/80.

C. and D. Electrocardiograms still showed flat $\mathrm{T}$ waves in leads I, II, III, $\mathrm{aV}_{\mathrm{L}}, \mathrm{aV}_{\mathrm{F}}, \mathrm{V}_{4-8}$ on the first and eleventh postoperative days. Blood pressure was $120 / 85$ and plasma $\mathrm{K}$ was $4.9 \mathrm{mEq} . / \mathrm{L}$. on the eleventh postoperative day. 
grams. Other physical and laboratory examinations revealed dwarfism, hypoplasia of the sexual organ, mental retardation and psychomotor seizures. Investigations also showed a cerebrospinal fluid pressure of $100 \mathrm{~mm}$. in water, low excretion of 17-O. H. C. S., total plasma cholesterol of $154 \mathrm{mg}$., serum potassium of $4.1 \mathrm{mEq}$./L., phenolsulfonphthalein excretion of $65 \%$ in 2 hours, protein-bound-iodine of $3.7 \gamma /$ $100 \mathrm{ml}$. and normal type of Mecholyl test. Blood pressure was 98/64 and no cardiac enlargement was revealed in the chest skiagram. Preoperative electrocardiograms were within normal limits, as shown in Fig. 1. Partial removal of the tumor was made by the left frontal approach under general anaesthesia with premedication of $10 \mathrm{mg}$. of atropine sulfate. The patient stood the operative procedure of one hour and 45 minutes quite well. Electrocardiograms recorded immediately after the operation, revealed flat $\mathrm{T}$ waves in all leads. Similar electrocardiograms of low to flat $\mathrm{T}$ waves were sustained without any symptom and sign of impaired cardiovascular function for about 2 weeks after the operation, although moderate elevation of body temperature occurred for about 20 days postoperatively.

In our previous paper, ${ }^{1 "}$ it was shown in cases with general surgical diseases that abnormal $\mathrm{T}$ waves or depressed S-T segments immediately after the operation were less evident when the operation was done under general anaesthesia. In contrast, neurosurgical cases exhibited a higher incidence of abnormal patterns (81\% in cases with craniopharyngioma, $67 \%$ in cases with hypophyseal adenoma and $57 \%$ in cases with other sellar tumors).

Except in a couple of cases showing slight decrease of $T / R$ ratio, $S-T$ segments and $\mathrm{T}$ waves were usually not changed during the operation even in cases with craniopharyngioma or with hypophyseal adenoma, although the Q-T interval was prolonged above the normal range in most of the serial electrocardiograms recorded during the operation. But, in a case with hypophyseal adenoma, the $T$ waves in leads II and $V_{4}$ revealed a strong tendency of being biphasic when the operative procedure approached the hypophyseal region. The fact, that abnormal $T$ waves or S-T segments were not found during the operation even in cases with postoperatively induced abnormal electrocardiograms, might be due to sufficient oxygen supply during the operation.

Other abnormal electrocardiographic patterns found postoperatively in some cases, were as follows:

Case 2. A. I. 20-year-old male. Posttraumatic epilepsy.

The patient had a skull fracture at the right parietal region at the age of 5 , and sustained left spastic hemiplegia. He suffered attacks of generalized convulsive seizures since 10 years of age. At 16 years of age, cranioplasty was done at a hospital, but convulsive seizures could not be controlled by the medication. The patient was admitted to the hospital for right hemispherectomy. Physical examinations revealed left sided spastic hemiplegia, repeated generalized convulsive seizures, mental retardation, a blood pressure of 130/80 and no evidence of cardiovascular impairment. Right hemispherectomy was performed under general anaesthesia. Moderate fever and impaired consciousness occurred during the first 
several postoperative days, but the patient was allowed to stand and walk 3 weeks after the operation. Preoperative electrocardiograms were within normal limits, but bursts of short P-Q intervals with abnormal QRS complexes were revealed in all leads thereafter when the right cerebral artery was ligated, and sustained until 6 hours after the conclusion of the operation. There was S-T segments depression during the first several postoperative days (Fig. 2).

Case 3. T. T. 32-year-old female. Hypophyseal adenoma.

The patient had noticed amenorrhea for the past 4 years, and had impairment of left visual acuity since 3 years ago. Physical examinations revealed left optic nerve atrophy with temporal hemianopsia, cerebrospinal fluid pressure of $180 \mathrm{~mm}$. in water and a blood pressure of 110/72. No cardiovascular impairment was observed. Preoperative electrocardiograms were essentially normal. After subcapsular removal of the adenoma, moderate fever, nuchal rigidity and leucocytosis developed for the 10 postoperative days. Electrocardiograms of the first postopera-

A.

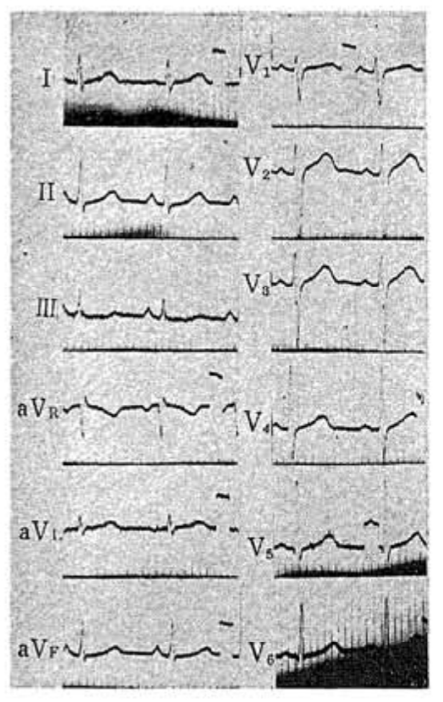

B.

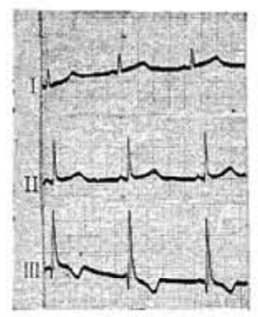

a.

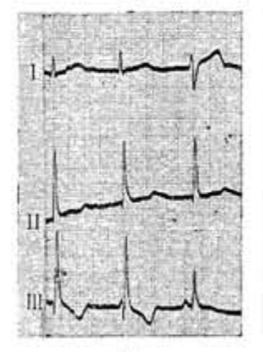

c.

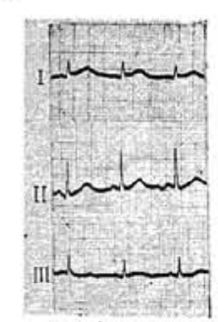

b.

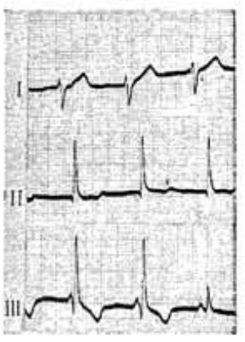

d.

Fig. 2. A. T. 21-year-old male. Posttraumatic epilepsy and left sided spastic hemiplegia with mental retardation.

A. Preoperatively, electrocardiograms were within normal limits, except $P$ waves of $0.3 \mathrm{mV}$. in standard and extremity leads. Blood pressure was $130 / 80$.

B. Right hemispherectomy was done under general anesthesia. On serial electrocardiograms recorded during the operation, bursts of different amplitude and height of QRS complexes with accelerating A-V conduction occurred occasionally in association with a regular sinus rhythm thereafter when right anterior cerebral artery was tied $(a-d)$.

a. Right internal carotid artery tied. B.P. $130 / 94$ b. Right anterior cerebral artery tied. B. P. $122 / 94$ c. Brain tissuses near the basal ganglion resected. B. P. $130 / 88$ d. Right occipital lobe manipulated. B. P. $122 / 82$ 
C.

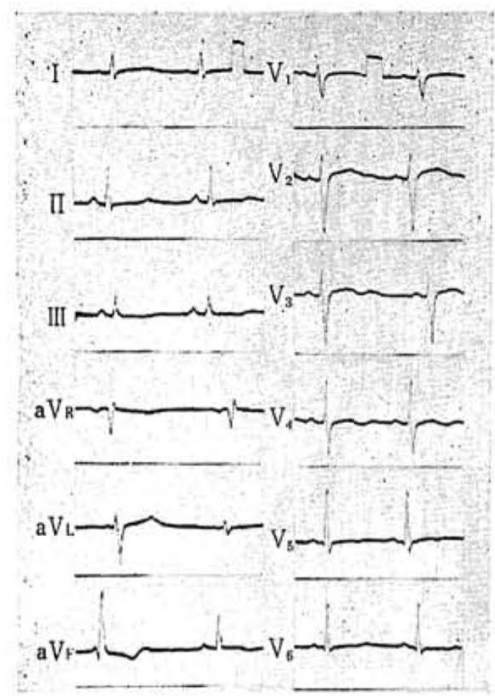

D.

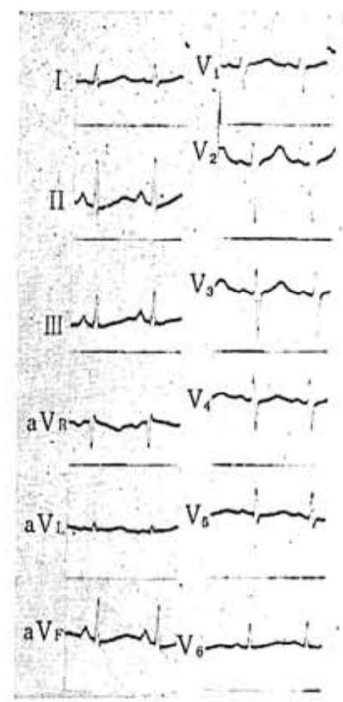

C. The abnormal patterns of $\mathrm{P}-\mathrm{Q}$ intervals and $\mathrm{QRS}$ complexes sustained until about six hours after the conclusion of the operation. Electrocardiograms recorded $\mathbb{I}$ six hours after operation, revealed low-to-flat $\mathrm{T}$ waves in leads $\mathrm{I}, \mathrm{II}, \mathrm{aV}_{\mathrm{L}}, \mathrm{V}_{1-6}$ and slightly inverted $\mathrm{T}$ waves in leads III, $\mathrm{aV}_{\mathrm{F}}$. Blood pressure was 120/58.

D. On the first postoperative day, $\mathrm{T}$ waves were low in leads II, III, $a V_{\mathrm{F}}, \mathrm{V}_{\mathbf{4 - 6}}$, and $\mathrm{S}-\mathrm{T}$ segments depression appeared in leads II, III, $a V_{\mathrm{F}}$. Blood pressure was $120 / 70$.

tive day revealed multifocal, ventricular premature beats as seen in Fig. 3, withou any evidence of circulatory disturbance.

Case 4. Y. Y. 41-year-old male. Recurrent hypophyseal adenoma.

The previous operation of hypophyseal adenoma was performed 3 years ago, but recently the patient exhibited clinical symptoms and signs of recurrent tumor. Physical examinations revealed optic nerve atrophy with bitemporal hemianopsia, cerebrospinal fluid pressure of $150 \mathrm{~mm}$. in water, blood pressure of $84 / 60$ and no cardiac enlargement. Preoperative electrocardiograms disclosed the incomplete right bundle branch block (Fig. 4). Subcapsular, partial removal of the tumor was made through the frontal route under general anaesthesia. After the conclusion of craniotomy, the general condition deteriorated. Blood pressure rose to $158 / 106$ and the patient showed drowsiness, anisocoria and hyperthermia. About 17 hours after the first operation, re-exploration of the right frontal and hypophyseal regions revealed a small epidural haematoma with a small-sized blood clot in the region of the anterior clinoid process and oozing from the tumor tissue. After the second operation, the patient's status remained unchanged, and respiration was assisted. Twenty-two hours after the first operation, blood pressure became $70 / 60$ and body temperature was elevated to $42^{\circ} \mathrm{C}$. Electrocardiograms during this period revealed sinus tachycardia with complete right bundle branch block, showing more serious impairment of intraventricular conduction system. The 


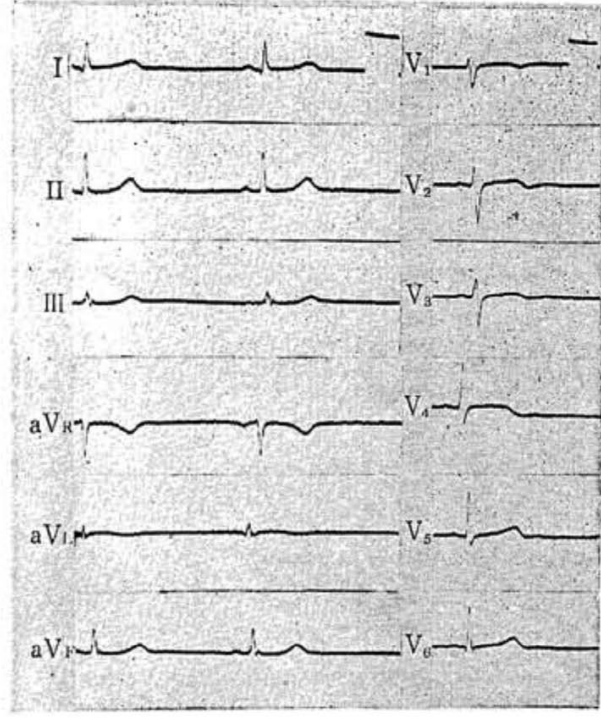

A.

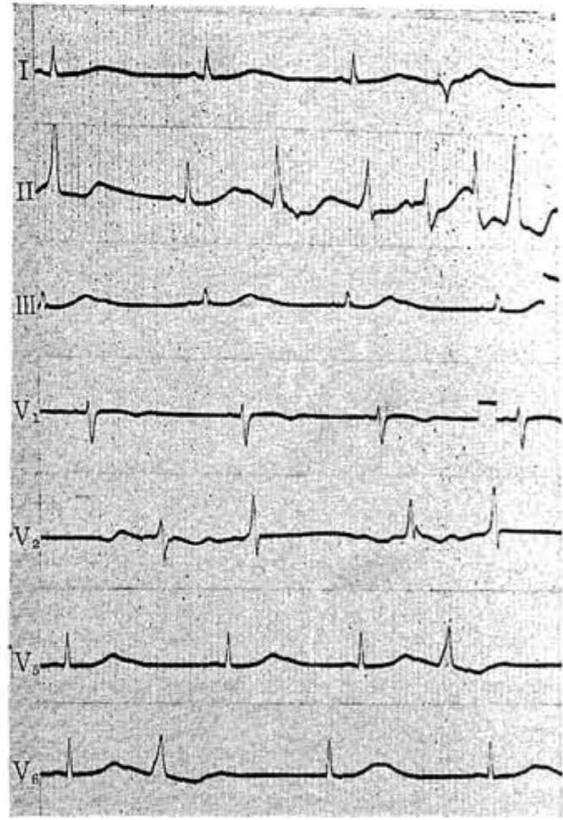

B.

Fig. 3. T.T. 32-year-old female with hypophyseal adenoma.

A. Preoperative electrocardiograms showed sinus bradycardia with normal QRS complexes, S-T segments and T waves. Blood pressure was 110/72.

B. Left frontal craniotomy and subcapsular removal of the adenoma were done under general anesthesia. On the first postoperative day, multifocal, ventricular premature beats were seen in association with a regular sinus rhythm, and blood pressure was $124 / 90$.

patient died 2 hours later, and autopsy revealed large hypophyseal adenoma compressing the ventral portion of the pons.

It is of interest to know that a high incidence of abnormal electrocardiographic patterns occurred postoperatively in cases with neurosurgical lesions, but when discussing the correlation between brain surgery and postoperative abnormal electrocardiograms, we should bear in mind that the changes in the postoperative electrocardiograms might be due to some functional mechanism.

Most cases with cerebrovascular accidents were associated with impairment of coronary artery and myocardium, and, therefore, there were many occasions where it was very difficult to obtain any information as to whether or not there was any relation between brain damage itself and electrocardiographic abnormalities.

We could find just the same situation in neurosurgical cases as in the cases with cerebrovascular accidents.

Case 5. T. T. 51-year-old male. Subarachnoid hemorrhage. 


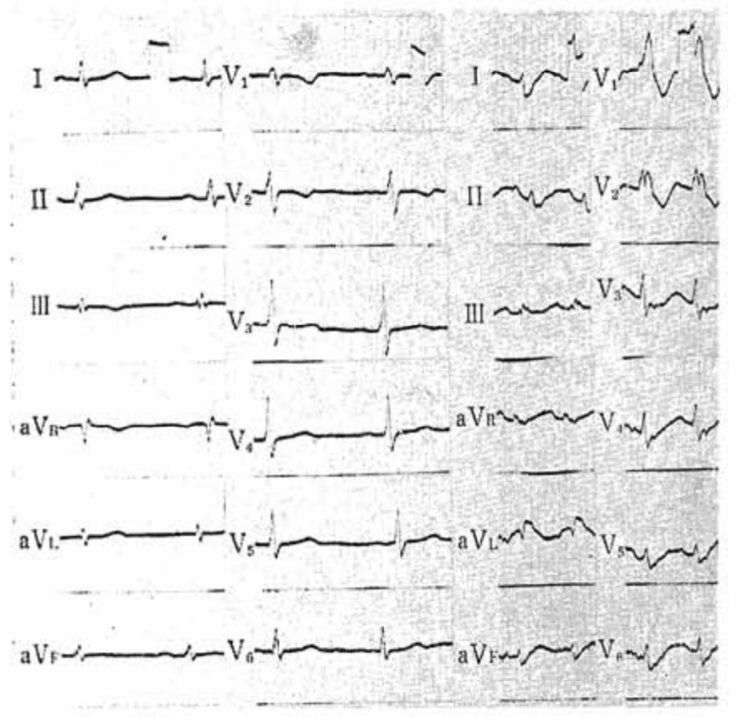

A.

B.

Fig. 4. Y.Y. 41-year-old male with recurrent hypophyseal adenoma.

A. Presperative electrocardiograms disclosed slightly wide QRS complexes in standard and extremity leads and atypical late $\mathrm{R}$ in $\mathrm{V}_{1-2}$.

B. On the first postoperative day when general condition had deteriorated, electrocardiograms revealed sinus tachycardia with complete right bundle branch block in association with flat $\mathrm{T}$ waves. Blood pressure was $80 / 50$.

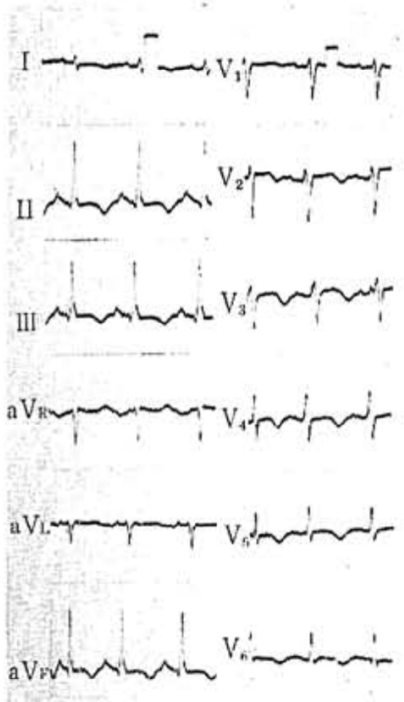

Fig. 5. T. T. 5l-year-sld male with subarachnoid hemorrhage due to a ruptured aneurysm of anterior communicating artcry.

On the second day of admission, electrocardiographic prtterns revealed sinus tachycardia with inverted $\mathrm{T}$ waves in leads I, II, III, a $\mathrm{F}_{\mathrm{F}}, \mathrm{V}_{2-6}$. $P$ waves were shown over $0.3 \mathrm{mV}$. in standerd leads.

Fifteen days before the admission to the surgical department, the patient was drunk and fell against a corner of a desk, with resultant unconsciousness for about one hour. Six days later, the patient complained of severe occipital headache and his consciousness was impaired. On the day of the admission, physical examination revealed delirium, signs of meningeal irritation, tonic neck reflex, choked discs, facial palsy and loss of superficial reflexes on the left side. Blood pressure of 130/100, and blood-stained cerebrospinal fluid with increased pressure of $350 \mathrm{~mm}$. in water. Repeated examinations of electrocardiograms revealed sinus tachycardia with inverted $\mathrm{T}$ waves (in leads $\mathrm{I}, \mathrm{II}, \mathrm{III}, \mathrm{aV}_{F}$ and $\mathrm{V}_{2-6}$ ) and S-T segments depession (in lead II, III and $\mathrm{aV}_{\mathrm{F}}$ ), as shown in Fig. 5. The patient's condition over the next 4 days deteriorated gradually with corresponding changes in symptoms and physical signs, complicated with bronchopneumonia. He succumbed to the ailment on the fifth day. Autopsy revealed subarachnoid hemorrhage caused by a ruptured aneurysm at the site of the anterior communicating artery, marked swelling of the brain tissue and high grade sclerosis of the basilar artery. On the other hand, there were concentric hypertrophy of bilateral ventricles of the heart with diffuse subendocardial hemorrhage in the myocardium of the left ventricle, and with moderate sclerssis of left coronary artery, hemorrhagic bron- 
chopneumonia of bilateral lower lobes and arteriosclerotic kidneys.

This case demonstrated the difficulties in determining whether or not such an organic change as diffuse subendocardial hemorrhage was associated frequently with brain surgery and whether or not the abnormal electrocardiograms were traced by the postoperatively induced organic changes of the myocardium. Therefore, we must be meticulous in our consideration of any relationship between brain surgery and electrocardiograms.

\section{Discussion}

As described above, Aschenbrenner and Bodechtel ${ }^{10)}$ reported, over 20 years ago, on several young patients that abnormal electrocardiograms were frequently observed after brain surgery. Our findings in 323 cases with neurosurgical lesions were essentially similar to those of Aschenbrenner and Bodechtel, and furthermore, we noted with great interest that abnormal electrocardiographic patterns were most frequently observed after operations in the sellar region (in cases with craniopharyngioma, hypophyseal adenoma and other sellar tumors). The exact mechanism which induces abnormal electrocardiograms frequently after brain surgery has been poorly understood, but 2 factors might be regarded as the principal causes:

1) Influences caused by general surgical stress:

Various operative procedures, acting as a general stressor, might cause such impairments as hypotension, hyper-or hypopotassemia, hypoxia, hypercapnea, anemia, impaired liver function and so on. Each of these might possibly influence the postoperative electrocardiographic patterns even in cases with neurosurgical lesions. Therefore, various kinds of clinical and laboratory findings were carefully examined to obtain any information about the causal factor inducing postoperative abnormal electrocardiograms.

a) Age: The average age of these neurosurgical cases was rather young, and there was no definite difference in the incidence of abnormal $\mathrm{S}-\mathrm{T}$ segments and $\mathrm{T}$ waves among the various age groups for cranio-

Table VI. Incidences of Abnormal T Waves and S-T Segments Depression Postoperatively Induced in Cases with Craniopharyngioma, Hypophyseal Adenoma and Other Sellar Tumors

\begin{tabular}{ccc:ccc} 
Age & & $\begin{array}{c}\text { Incidence of } \\
\text { abnormal patterns }\end{array}$ & Age & \multicolumn{1}{c}{$\begin{array}{c}\text { Incidence of } \\
\text { abnormal patterns }\end{array}$} \\
$0-9$ & (1 case $)$ & $100 \%$ & $40-49$ & $(14$ cases $)$ & $64.3 \%$ \\
$10-19$ & (8 cases $)$ & $87.5 \%$ & $50-59$ & $(7$ cases $)$ & $71.4 \%$ \\
$20-29$ & (7 cases $)$ & $71.4 \%$ & over 60 & (2 cases) & $100 \%$
\end{tabular}

30-39 (7 cases) $\quad \mathbf{5 7 . 1 \%}$ 
pharyngioma, hypophyseal adenoma and other sellar tumors (Table VI). Therefore, age could not be considered as one of the main causal factors which induced postoperative abnormal electrocardiograms frequently in cases with neurosurgical lesions.

b) Coexistence of cardiovascular disorders (hypertension, arteriosclerosis and so on): In our previous paper, ${ }^{1)}$ it was shown that postoperative abnormal electrocardiograms might be induced much more frequently in cases associated with hypertension or with arteriosclerosis than in the control group, but this was not found in most of cases with craniopharyngioma, hypophyseal adenoma and other sellar tumors.

c) Fluctuation of blood pressure during operation and at the postoperative period: Even during long operative periods in the supine position and during the postoperative periods, the blood pressure remained at a constant level in most cases with craniopharyngioma, hypophyseal adenoma and other sellar tumors, which induced high incidence of abnormal electrocardiograms postoperatively. On the other hand, in cases with infratentorial tumors, operations were performed with the patient in the face-down position. In this position, it was rather more difficult to maintain general circulation in a normal range than in a supine position, but the incidence of inducing abnormal patterns, except sinus tachycardia, on the electrocardiograms was much lower than in cases with other lesions.

It is unreasonable to suppose that the high indicidence of abnormal electrocardiograms is usually caused by any fluctuation of the blood pressure in cases with neurosurgical lesions.

d) Electrolyte balance: It might be possibly considered that impaired balance of electrolytes could be induced after causing the surgical stress to the hypophysis-hypothalamic region, but in our cases, there was no evidence to support this possibility, at least, from the standpoint of the incidence of hypopotassemia. ${ }^{21}$ Postoperative hypopotassemia occurred frequently in general surgical cases when postoperative parenteral administration of potassium-deficient fluid was continued for long periods, but in neurosurgical cases, most patients could take food by mouth or by nasal tubing from the early postoperative days, and therefore, it could be supposed that, in general, most neurosurgical patients did not exhibit marked hypopotassemia or potassium deficiency.

e) Postoperative anaemia: It was our coworker, Yokoyama, ${ }^{21}$ who stressed the high incidence of postoperative anaemia in neurosurgical patients who had operations in the supratentorial region, especially the base of the brain. But, when considering that it was rather rare to find abnormal S-T segments and flat or inverted $\mathrm{T}$ waves in chronic anaemia or even in the stage of acute anaemia due to gastric hemorrhage in younger patients, postoperative anaemia in neurosurgical cases could not be considered as a causal factor of abnormal electrocardiograms. 
f) Increased intracranial pressure: Incidence of postoperative $a b-$ normalities in the electrocardiograms was low in cases with infratentorial tumors associated with increased intracranial pressure, and on the other hand, it was markedly high in cases with craniopharyngioma and hypophyseal adenoma without any evidence of postoperative rise in intracranial pressure. Therefore, increased intracranial pressure itself could not be considered as an important factor.

g) Hypoxia: During the postoperative period, $\mathrm{pO}_{2}$ in blood was slightly reduced and $\mathrm{pCO}_{2}$ was slightly elevated even for a short duration in some of the neurosurgical cases just as in general surgical cases. In a case with subdural hematoma, a 69-year-old male, preoperative electrocardiograms were within normal limits, but inverted $\mathrm{T}$ waves with sinus tachycardia were seen in postoperative electrocardiograms. As the patient was comatose on the third postoperative day, the second exploration was made under endotracheal oxygen supply with muscle relaxant. The postoperatively induced inverted $\mathrm{T}$ waves reverted to normal positive $\mathrm{T}$ waves with sinus tachycardia at the conclusion of the reexploration against postoperative epidural hematoma. We also found in many neurosurgical cases with long-duration of apnea whose respiration had to be assisted and electrocardiograms were within normal limits. These cases showed that postoperative hypoxia, due to various causes, influenced electrocardiographic patterns as frequently in the neurosurgical cases as in general surgical cases, although we tried, in each occasion, to administer sufficient oxygen by nasal catheter.

From the discussions mentioned in above, we could not find any definite and common factor among possible causes with an exception of hypoxia. Although each of these factors gave just a slight influence to the electrocardiographic patterns, they might be able to induce mass collective abnormalities on the electrocardiograms with the coexistence of several factors. Further attempts should be directed toward elucidating factors responsible for postoperative abnormal electrocardiograms.

2) Influences caused by neural factor:

As Wassermann ${ }^{10)}$ described in his paper on the induction of abnormal electrocardiograms associated with cerebrovascular accidents, various areas of the central nervous system might be affected both directly or indirectly after brain surgery. For example, the impairment of electrolytes and fluid balance could be induced by surgical damage of the brain, and then could affect the function of the heart indirectly. ${ }^{10}$ ) On the other hand, the inhibitory and augmented center of the cardiovascular system lies in close proximity of the medulla oblongata in the floor of the fourth ventricle, and its highest center is found in the region of the hypothalamus and the frontotemporal and parietal lobes. ${ }^{22-25}$ Therefore, surgical damage in close proximity to these areas, might also cause functional alterations of 
the heart muscle or might affect cardiac rhythm directly. In 1922, Lennox, Graves and Levine ${ }^{26)}$ reported that abnormalities of the electrocardiograms were observed more frequently in cases with intracranial or cervical operations than in cases with operations on other areas, and that only the factors which might be concerned with alterations in vagal tone, seemed to be of importance in the induction of the abnormalities. We must then consider whether or not it was possible for cardiac function to be influenced through the neural pathway by direct surgical attack on the hypophyseal or hypothalamic region. There was evidence to support this idea in our series:

Firstly, most cases with operation on the hypophyseal region exhibited rather long R-R intervals both pre- and postoperatively, but many cases with lesions at other areas of the brain, especially at the infratentorial region, were generally associated with short $\mathrm{R}-\mathrm{R}$ intervals during the early postoperative days. This result supported Takeuchi's clinical view ${ }^{27}$ that

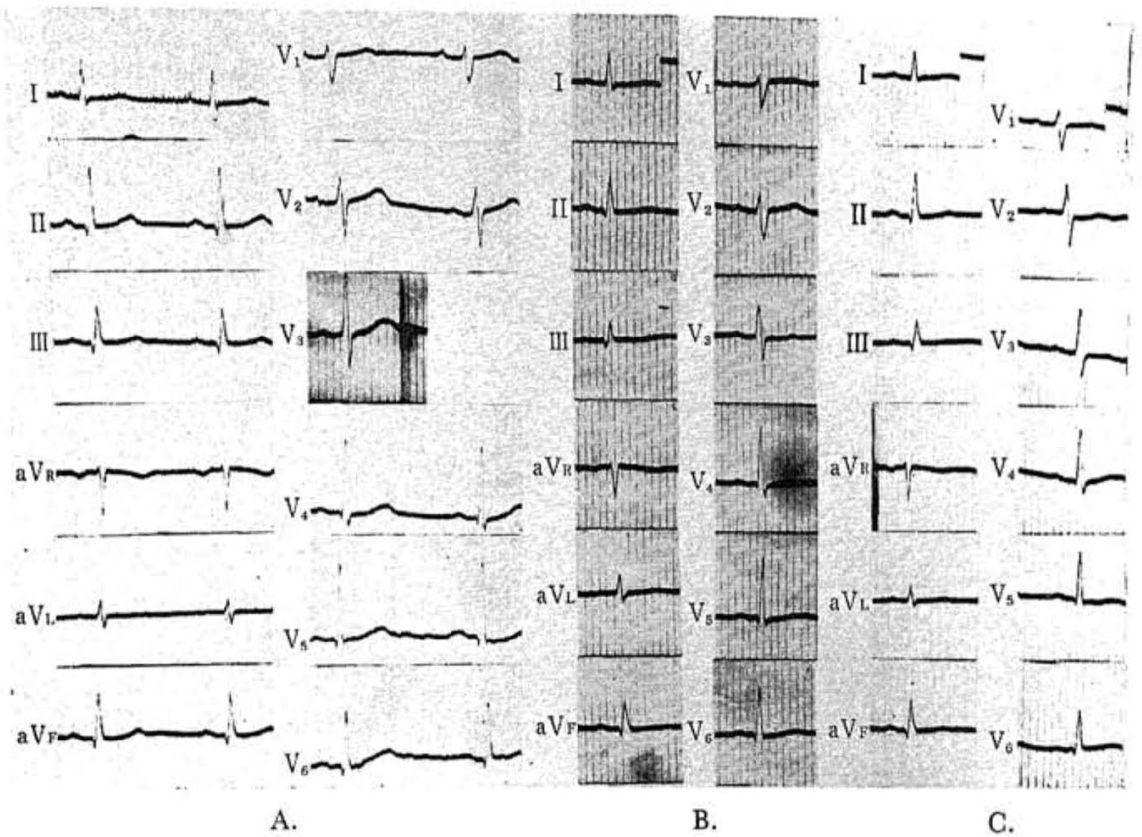

Fig. 6. K. I. 45-year-old male with craniopharyngioma.

A. Preoperative electrocardiograms were within normal limits. Laboratory findings showed blood pressure of 120/82, hematocrit of $40.9 \%$ and plasma K of $3.9 \mathrm{mEq} . / \mathrm{L}$. (July, 1959).

B. Left frontal craniotomy was done to remove the cyst. Electrocardiographic patterns were flat $\mathrm{T}$ waves in all leads on the first postoperative day. Blood pressure was 120/80.

C. Flat $T$ waves still remained on the second postoperative day, when blood pressure was $118 / 78$ with hematocrit of $36.0 \%$ and with plasma $\mathrm{K}$ of $4.2 \mathrm{mEq} . / \mathrm{L}$. 


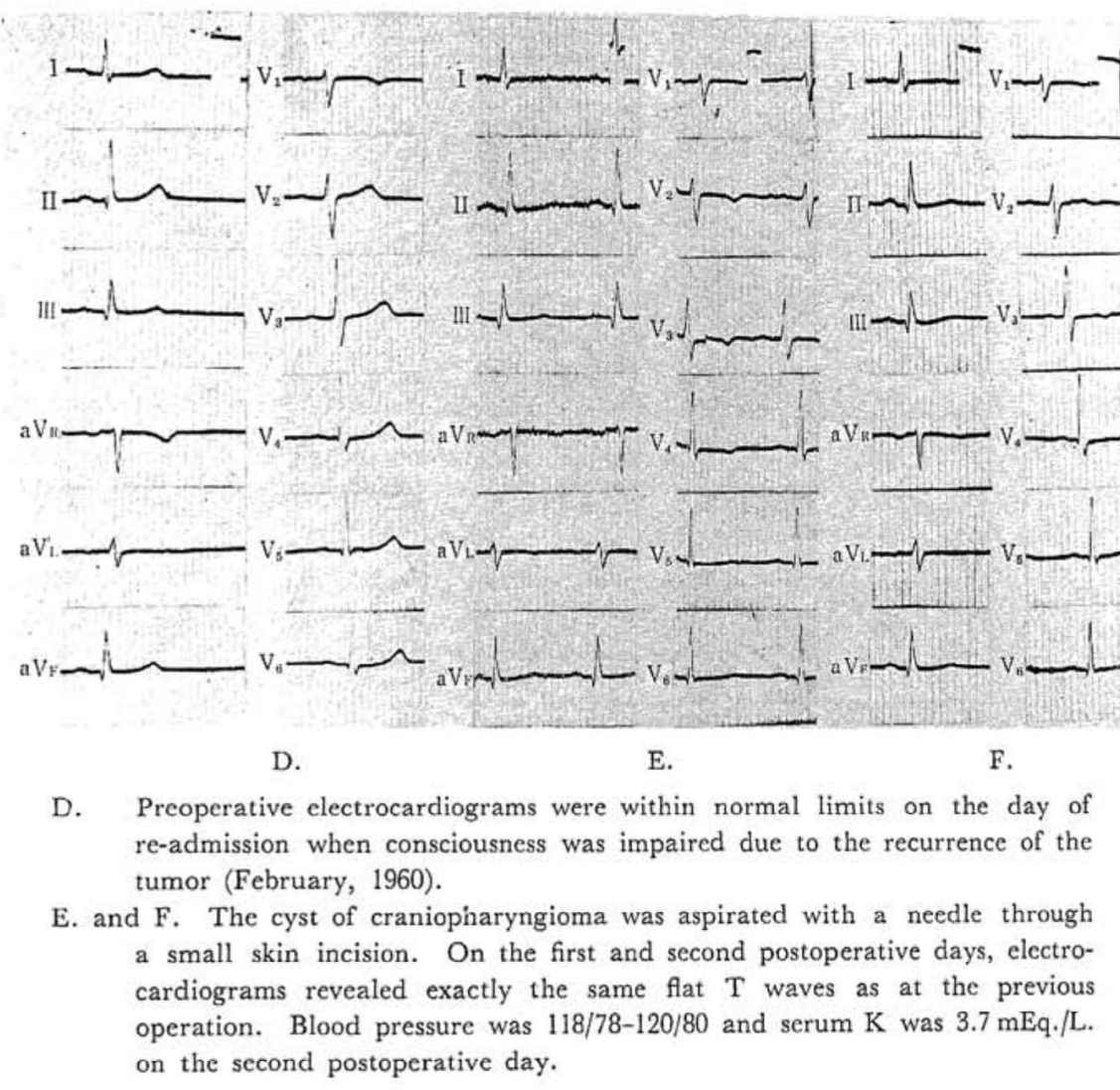

the elevation of the base of the frontal lobe with the brain spatula induced sinus bradycardia during the operation. Kamiya, Ohaku, Akiyama and Nakamura ${ }^{28}$ ) reported that, although tachycardia and the lowering of peripheral digital plethysmograms were exhibited during brain surgery, bradycardia and the increase in the amplitude of plethysmograms were found occasionally when the surgical procedures involved the hypothalamic region.

These clinical findings might be supported by various experimental studies on circulatory changes caused by chemical or electrical stimulations of the hypothalamic region. ${ }^{29)-82}$

Secondly, it was of considerable practical significance that similar electrocardiographic patterns were observed after 2 different operations on the same patient, as shown in Fig. 6 .

Case 8. K. I. 45-year-old male with craniopharyngioma.

The first frontal craniotomy was done 3 years ago, and when the patient had the second craniotomy 9 months ago (July, 1959) to remove the recurrent craniopharyngioma electrocardiograms showed flattenning of $\mathrm{T}$ waves immediately after the operation and for the first postoperative day. The patient was re-admitted to 
the surgical department because of impaired consciousness due to the recurrence of the tumor (February, 1960).

The electrocardiogram was within normal limits on the day of admission, but immediately after the operation when the cyst of craniopharyngioma was aspirated with a needle through a small skin incision, and on the first postoperative day, the electrocardiograms revealed exactly the same $\mathrm{T}$ waves change as at the previous operation.

It would be of interest to know that similar electrocardiographic patterns were induced postoperatively in the same patient on different occasions, although the nature of the operation varied. The result might show that some of electrocardiographic abnormalities could be induced by neural factors directly or indirectly from special areas of the central nervous system.

Thirdly, we could consider a special $\mathrm{T}$ waves pattern. Burch" described the so-called "large negative $\mathrm{T}$ waves" associated with cerebrovascular accidents as a new electrocardiographic pattern, and attributed this abnormal pattern of electrocardiogram to a neural factor. Similar electro-

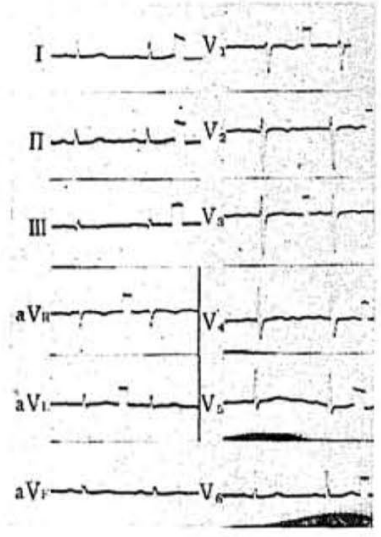

A.

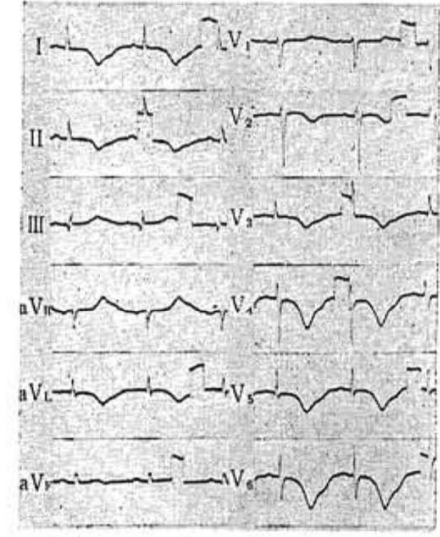

B.

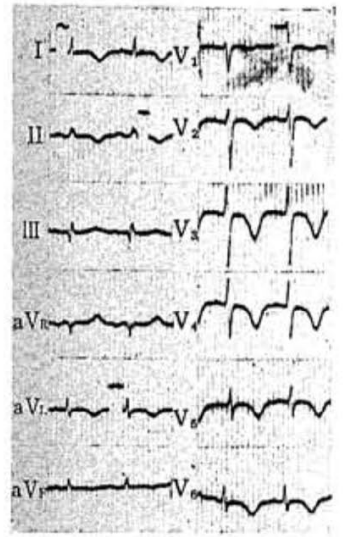

C.

Fig. 7. N.T. 40-year-old female with metastatic cancer of left frontotemporal lobe.

A. Preoperative electrocardiograms showed low $\mathrm{T}$ waves in precordial leads. Blood pressure was 130/70. Physical and laboratory examinations showed a cerebrospinal fluid pressure of $280 \mathrm{~mm}$. in water, hematocrit of $40.0 \%$, plasma $\mathrm{Na}$ of $140 \mathrm{mEq} . / \mathrm{L}$., plasma $\mathrm{K}$ of $4.5 \mathrm{mEq} . / \mathrm{L}$. and plasma $\mathrm{Cl}$ of $101 \mathrm{mEq} . / \mathrm{L}$.

B. Left fronto-temporal decompression and biopsy of the tumor tissue were done under general anesthesia. On the first postoperative day, blood pressure was 120/70, but electrocardiograms revealed prolonged Q-T intervals and large negative $T$ waves in leads $I, I I, a V_{L}, V_{3-6}$. It was found that large negative $T$ waves and $U$ waves jointly gave rise to large negative waves.

C. Even on the eleventh postoperative day, the similar patterns were still found as on the first postoperative day. Blood pressure 124/80, plasma $\mathrm{K} 4.4 \mathrm{mEq} . / \mathrm{L}$., and no evidence of cardiovascular impairment. 
cardiograms were observed in 3 cases with neurosurgical lesions (meningioma of the orbital surface, falx-meningioma and metastatic tumor of left fronto-temporal lobe), as illustrated in Fig. 7. The pattern of electrocardiograms consisted of prolonged Q-T interval and negative $\mathrm{T}$ waves of considerable amplitude and width, as described by some authors. In some cases, it was found that large negative $\mathrm{T}$ waves and $\mathrm{U}$ waves jointly gave rise to large negative waves. Although Levine, ${ }^{38)}$ Ippolito et al., ${ }^{34)}$ Pruitt et al., ${ }^{35}$ Garcia-Palmieri et al. ${ }^{36)}$ and Goldman ${ }^{37}$ reported that the large negative $\mathrm{T}$ waves were exhibited in cases with coronary heart disease and that an important factor was seemingly the existence of a coronary insult, we found that the peculiar patterns were not associated with any symptom and sign of evident cardiac and circulatory impairments. They were reverted to normal patterns when the clinical condition improved. We observed 3 other cases with large negative $T$ waves induced after laparotmy and thoracotomy. It might be possible to consider the correlation between a neural factor, especially the vagal nerve, and the large negative $T$ waves, as suggested by Burch, ${ }^{\prime)}$ but this subject needs further study.

From these various data, it may be suggested that the electrocardiographic patterns could also be affected by surgical damage to the special areas of the central nervous system directly through the neural pathways. However, further investigations are needed since these abnormal patterns might also be caused possibly by various impaired functions induced after brain surgery.

\section{Summary}

(1) Evidence has been presented in 323 neurosurgical cases that serial electrocardiograms exhibited high incidence of postoperative abnormal patterns in cases with intracranial surgical lesions, especially with tumors near the sellar region (craniopharyngioma, hypophyseal adenoma and other sellar tumors) and with the fronto-temporal lobe tumors. Most of the abnormalities in the electrocardiograms consisted of flat or inverted $\mathrm{T}$ waves and S-T segments depression, but the incidence of abnormal $\mathrm{S}-\mathrm{T}$ segments was much less than that of abnormal $\mathrm{T}$ waves.

(2) The mechanism of inducing these phenomena has been briefly discussed. It has been suggested that electrocardiographic patterns might be affected by a neural factor after direct or indirect surgical damage to the parapituitary areas of the central nervous system.

(Read before the 24th Annual Session of the Japanese Circulation Society, Osaka, Japan, April 1st. 1960.) 


\section{REFERENCES}

1. Hayashi, S. and Miyagawa, S.: Naika (Internal Mdicine) 4: 1056, 1959 (In Japanese).

2. Lucke, H.: Dtsch. Arch. klin. Med. 180: 40, 1937.

3. Abott, W.P. and Fay, O.J.: J.A. M. A. 116: 1052, 1942.

4. Weber, A.: Dtsch. med. Wschr. 76: 1616, 1951.

5. Dietrich, A.: Dtsch. med. Wschr. 77: 1181, 1952.

6. Byer, E., Ashman, R., and Toth, L. A.: Am. Heart J. 33 : 796, 1947.

7. Lepeschkin, E. : Modern Electrocardiography (Vol. 1), Williams and Wilkins, Baltimore, 1951.

8. Levine, H.: Am. Heart J. 15 : 344, 1953.

9. Burch, G. E., Meyers, R., and Abildskow, J. A.: Circulation. 9 : 719, 1954.

10. Wassermann, F., Choquette, G. C., Cassinelli, R., and Bellet, S. : Am. J. Med. Sci. 231: 502, 1956.

11. Gruneis, P.: Wien. med. Wschr. 106: 91, 1956.

12. Kaunistro, Y.: Cited by 16) Kehrer, H. E.

13. Abeles, M. and Schneider, D.: Am. J. Med. Sci. $190: 673,1935$.

14. Brenner, W.: Z. Kinderheilkunde 63: 151, 1942.

15. Hoff, F. and Fluch, M.: Münch. med. Wschr. $90: 503,1943$.

16. Kehrer, H.E.: Dtsch. med. Wscher. 72: 288, 1947.

17. Bayer, O. and Stroder, J.: Dtsch. med. Wschr. 74: 824, 1949.

18. Schaper, G.: Monatsschr. Kinderh. 103: 14, 1955.

19. Aschenbrenner, R. and Bodechtel, G.: Klin. Wschr. 17: 298, 1938.

20. Bartelheimer, H.: Dtsch. med. Wschr. 72: 382, 1947.

21. Yokoyama, T.: Recent Advance in Research of the Nervous System 4: 423, 1960 (In Japanese).

22. Kaada, B., Pribram, K., and Epstein, J.: J. Neurophysiol. 12 : 347, 1949.

23. Chapman, W.P., Livingston, K.E., and Poppen, J.L.: J. Neuropysiol. 13: 65, 1950.

24. MacLean, P. D. and Delagdo, J. M. R. : E. E. G. and Clinical Neurophysiol. 5: 91, 1953.

25. Friedman, M.: Functional Cardiovascular Disease, Williams and Wilkins Co. Baltimore, 1947. cited by Friedberg, C. K. Diseases of the Heart (2nd ed.), Williams and Wilkins Co. Baltimore, 1956.

26. Lennox, W. G., Graves, R. C., and Levine, S. A.: Arch. Int. Med. 30: 57, 1922.

27. Takeuchi, K.: No-to-Shinkei (Brain and Nerve) $10: 171,1958$ (In Japanese).

28. Kamiyama, K., Ohaku, M., Akiyama, S., and Nakamura, S.: No-toShinkei (Brain and Nerve) 11: 97, 1959 (In Japanese).

29. Beattie, J., Brow, G. R., and Long, C. N. H. : Proc. Royal Society (London) 106: 253, 1930. cited by 8) Levine, $\mathrm{H}$.

30. Dikshirt, B. B.: J. Physiol. 81: 382, 1934.

31. Watts, J. W. and Fulton, J. F. : Ann. Surg. 101: 363, 1935.

32. von Bogart, A.: cited by Korth, C. Dtsch. med. Wschr. 63: 449, 1938.

33. Levine, H. D. : Clinical heart disease (4th ed.), W. B. Saunders Co. Philadelphia, 1952. 
34. Ippolito, T. L., Blier, J. S., and Fox, T. T.: Am. Heart J. 48: 88, 1954.

35. Pruitt, R. D., Klakeg, C. H., and Chapin, L. E. : Circulation 11:517, 1955.

36. Garcia-Palmieri, M. R., Marchand, E.J., Diaz-Rivera, R. S., Santiago-Stevenson, D., and Fodrigviz, H. F.: Am. Heart J. 52: 521, 1956.

37. Goldman, M. J.: Principles of Clinical Electrocardiography (2nd ed.), Lange Medical Publications, Los Altos, Calif, 1958. 